\title{
Nonlinear Damping Identification in Precast Prestressed Reinforced Concrete Beams
}

\author{
P. Franchetti \& C. Modena \\ Department of Structural and Transportation Engineering, University of Padova, 9 via Marzolo, 35131 Padova, Italy
}

$\&$

M.Q. Feng

Department of Civil and Environmental Engineering, University of California, Irvine, CA 92697-2715, USA

\begin{abstract}
This article presents a damage detection method for prestressed reinforced concrete (PRC) elements based on free vibration tests and nonlinear damping identification. Integrated static and dynamic experiments were carried out on three precast PRC beam specimens. The static loading induced different levels of damage to the beams. At each damage level, impulsive loading was applied to the beams and the free vibration response was measured. The dynamic response data were processed using different methods including the multi-input multi-output (MIMO) curve fitting and the Hilbert transform techniques. A strong correlation is observed between the level of concrete damage (cracks) and the amount of nonlinear energy dissipation that can be modeled by means of quadratic damping. The nonlinear damping can be extracted from the free vibration response for each vibration mode. The proposed method is suited for quality control when manufacturing precast PRC members, and can be further extended for in situ detection of damage in concrete structures under ambient vibration.
\end{abstract}

${ }^{*}$ To whom correspondence should be addressed. E-mail: franchetti@dic.unipd.it.

\section{INTRODUCTION}

Over the past 30 years, damage detection from changes in structural dynamic parameters has received increasing attention in aerospace, mechanical, and civil engineering sectors (e.g., Cawley and Adams, 1979; Hunt et al., 1990; Jiang and Adeli, 2005, 2007, 2008a, 2008b; Adeli and Jiang, 2006; Pakrashi et al., 2007; Jiang et al., 2007; Park et al., 2007; Moaveni et al., 2008; Sohn et al., 2008; Carden and Brownjohn, 2008; He et al., 2008; Psimoulis and Stiros, 2008; $\mathrm{Li}$ and $\mathrm{Wu}, 2008$; $\mathrm{Ni}$ et al., 2008). Many techniques based on experimental modal analysis have been developed: they revolve around the fact that changes in physical properties cause detectable changes in modal parameters (including natural frequencies, mode shapes, modal damping), namely, the eigen-properties. In practice, the problem of damage detection is usually translated into identification of change in the modal parameters based on structural dynamic response measurement.

There are many remaining issues that make vibration-based damage identification difficult to implement in practice, particularly in civil engineering structures, which are usually complex with nonlinear behaviors of materials, uncertainties associated with boundary conditions, considerable sizes, and high damping. It is not always possible to conduct dynamic 
tests that provide a complete set of measurements to allow satisfactory modal extraction. Many of the proposed damage identification techniques require an undamaged baseline of the structure, which is usually difficult to obtain for real civil engineering structures. The work performed at the Los Alamos National Laboratory in the United States allowed researchers to compare the dynamic response before and after the introduction of different levels of damage (Farrar and Jauregui, 1998a, 1998b). Methods for locating damage without explicit reference to the undamaged state have also been proposed in the literature (Stubbs and Kim, 1996).

However, the frequency-domain linear techniques based on modal parameter extraction are not always sufficient to identify structural damage, because of the inelastic response and nonlinear damping of the structure associated with the damage. For this reason, Doebling et al. (1996) suggested a time-domain method to directly analyze time histories for indications of damage. Feng (2007) and Soyoz and Feng (2008) successfully identified, located, and quantified damage based on a nonlinear, time-domain extended Kalman filtering method.

In this study, the authors developed, through theoretical and experimental investigations, a damage detection method based on free vibration tests and nonlinear damping analysis. The original aim was for the quality control of the production of prestressed reinforced concrete (PRC) elements, which was motivated by the problem that the presence of cracking disqualifies a PRC product, reducing its serviceability performances and durability (Modena et al., 1998). Most of the experimental work originally focused on a single hollow-core floor panel, and the method was applied before and after controlled damage to the specimen (Modena et al., 1999; Sonda, 1999; Zonta, 2000). The experiments suffered from some limitations such as a limited number of tests, control of boundary conditions, a limited number of measuring points, and a lack of systematic analysis of the dynamic response related to the presence of damage, such as the frequency splitting (Zonta and Modena, 2001).

To overcome these limitations, new tests were performed in this study on three precast PRC beam elements characterized by different prestress levels used in practice, under controlled experimental environments in terms of boundary conditions and excitation sources. This study focuses on structural damping (that is not widely studied for damage detection in literature) and its change with regard to increase of damage, by means of not only classical linear damping model, but also nonlinear damping model calibrated with the measured vibration time histories. An unequivocal, but inexpress-
Table 1

Prestressing loads and strains for the three beam specimens

\begin{tabular}{lcc}
\hline & $\begin{array}{c}\text { Prestressing load } \\
(k N)\end{array}$ & $\begin{array}{c}\varepsilon_{\text {prestress -inf }} \\
(\%)\end{array}$ \\
\hline Beam A & 912 & -0.023 \\
Beam B & 1,172 & -0.034 \\
Beam C & 1,563 & -0.041 \\
\hline
\end{tabular}

ible in closed form, relationship was observed between the appearances of nonlinear damping and the presence and entity of damage. This article presents the damage detection method through an experimental study on the three precast PRC beams. This method can be extended for localizing the damage on precast beams, which is reported in Franchetti (2004), but not discussed in this article. This method can be also applied for in situ damage detection in concrete structures, as presented in Frizzarin et al. (2008).

\section{TEST PROGRAM}

Three precast PRC beams were fabricated and static and dynamic loading tests were carried out. Different levels of damage were induced to the specimens.

\subsection{Description of test beams}

Three 7.3-m long PRC beams with a rectangular crosssection were designed, as shown in Table 1 . The dimensions of these beams are shown in Figure 1. The total mass of each beam was $m=4,161 \mathrm{~kg}$ and the reinforced concrete density is $\rho=2,500 \mathrm{~kg} / \mathrm{m}^{3}$, neglecting the steel contribution. The reinforcement ratios of the beams were of $0.13 \%$ for ordinary reinforcement and of $0.2 \%, 0.26 \%$, and $0.35 \%$, respectively, for tendons of beams $\mathrm{A}, \mathrm{B}$, and $\mathrm{C}$, respectively.

To avoid the coupling effect between the horizontal and vertical bending modes, a width of $0.38 \mathrm{~m}$ was chosen that differed from the height of $0.60 \mathrm{~m}$. Reinforcement ratios are considered to be within a realistic range. By carefully choosing materials and designing the decompression loading, a large range of cracking and beam failures were obtained.

\subsection{Static and dynamic tests}

Integrated static and dynamic tests were conducted on the three beam specimens. The loading procedure is shown in Table 2. Table 3 shows the main outcomes 
PLAN

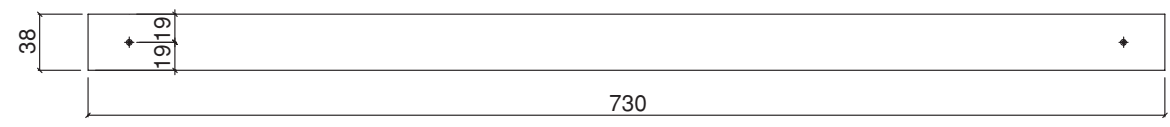

ELEVATION

2 DEHA anchors $(50 \mathrm{kN})$

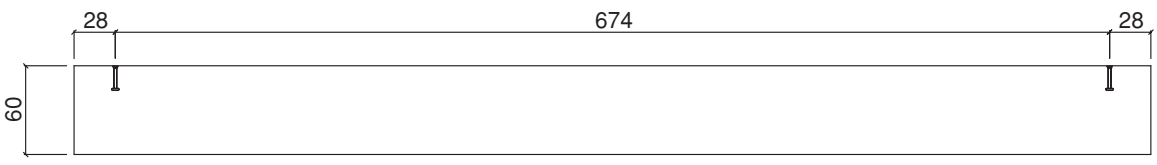

Fig. 1. Geometry of beam specimens.

Table 2

Testing procedure for each beam

\begin{tabular}{clc}
\hline Stage & \multicolumn{1}{c}{ Activity } & Damage state \\
\hline 1 & Dynamic measurement & D0 \\
2 & $\begin{array}{l}\text { Loading until decompression at the } \\
\text { lower side (D1) }\end{array}$ & \\
3 & Unloading & D1 \\
4 & Dynamic measurement & \\
5 & Loading until the opening of a & \\
& $\quad$ crack at the lower side (D2) & D2 \\
6 & Unloading & \\
7 & Dynamic measurement & D3 \\
8 & Loading until failure (state D3) & \\
10 & Unloading & \\
\hline
\end{tabular}

of loading tests for beam C. Damage was progressively induced to each of the beams by applying an asymmetrical static load with increasing monotonic intensity at one-third span, that is, $2.43 \mathrm{~m}$ from the closer edge, as shown in Figure 2. The beam was simply supported on two bearings at the ends. After each static load step, the static load was removed and dynamic testing was conducted using impulsive loading. Consequently, the dynamic characteristics of the test beams were obtained for the undamaged state D0 and each of the damaged states. As an example, the damage condition state D3 for beam $\mathrm{C}$ is shown in a photo in Figure 3. It is noted that dynamic loading was performed at different boundary conditions to avoid the influence of poorly defined boundary conditions on the identified modal parameters. For the dynamic testing, the beam was hung by two flexible springs, as shown in Figure 4, resulting in a much lower rigidbody first-mode rigid-body frequency than those of the elastic modes (approximately 1/10). Springs were anchored close to the beam ends. In this way, the rigid-body mode, which is entirely determined by its mass and the supporting springs, had a negligible effect on the elastic modes that were used for damage detection.

Table 3

Main outcomes of loading tests (beam C)

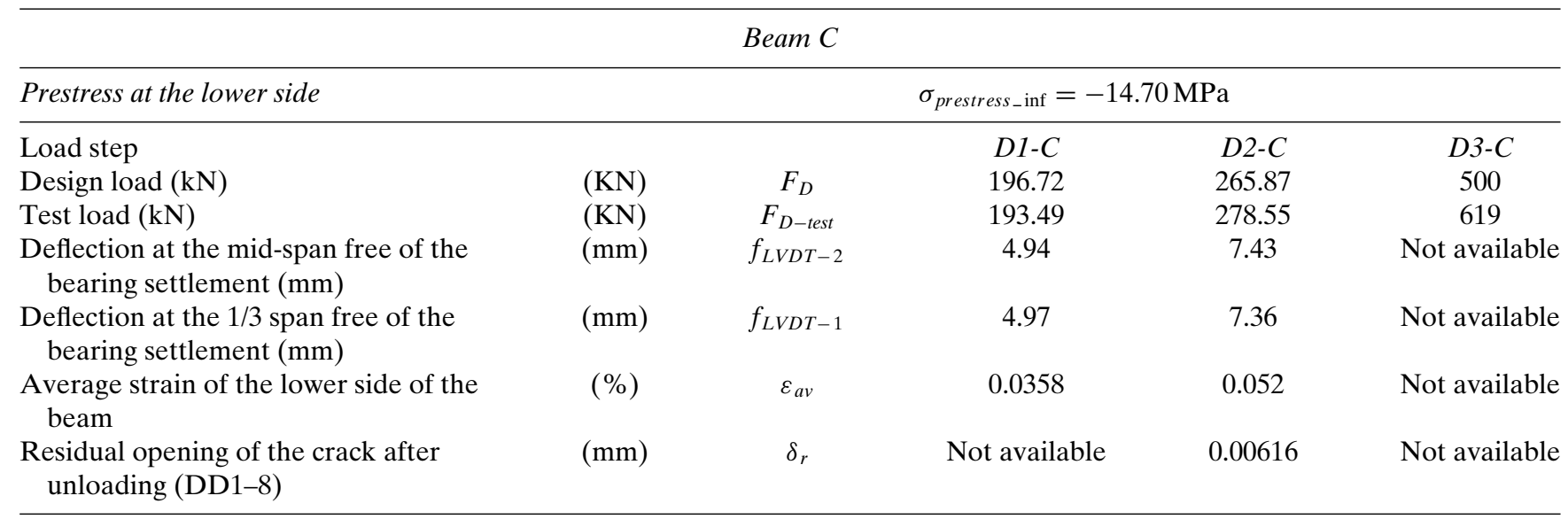


PLAN - TOP VIEW

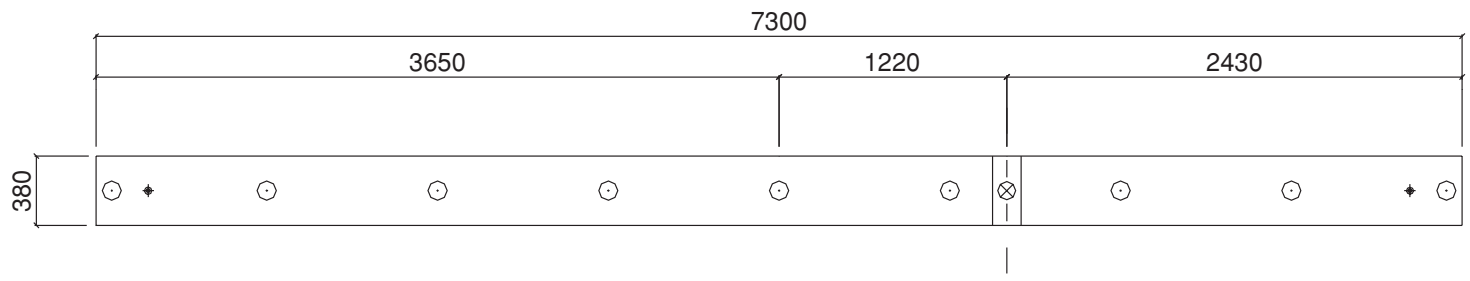

ELEVATION

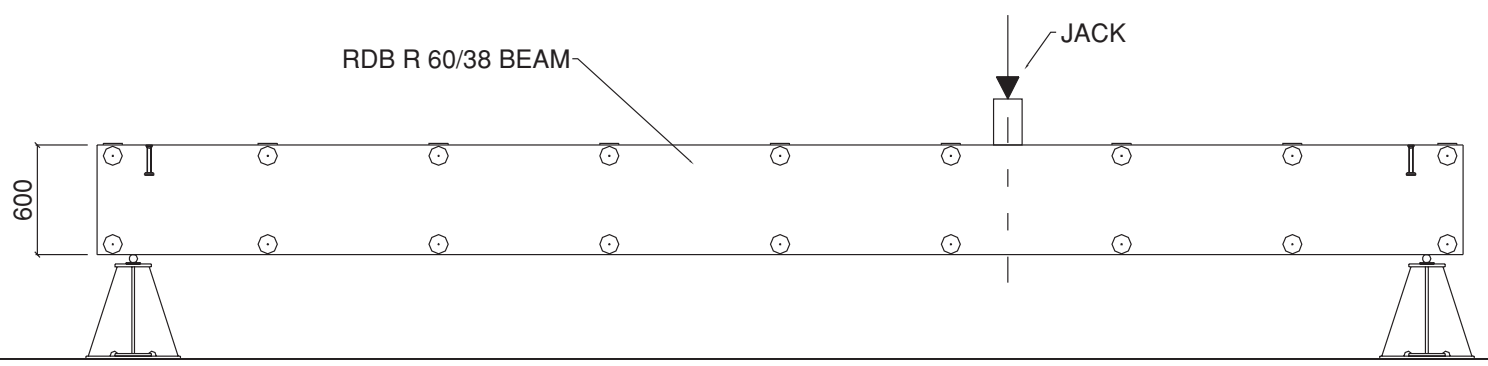

\begin{tabular}{|l|l|l|l|l|l|l|l|}
912,5 & 912,5 & 912,5 & 912,5 & 912,5 & 912,5 & 912,5 & 912,5 \\
\hline
\end{tabular}

STATIC LOAD TESTS - INSTRUMENTS SET-UP - BOTTOM VIEW

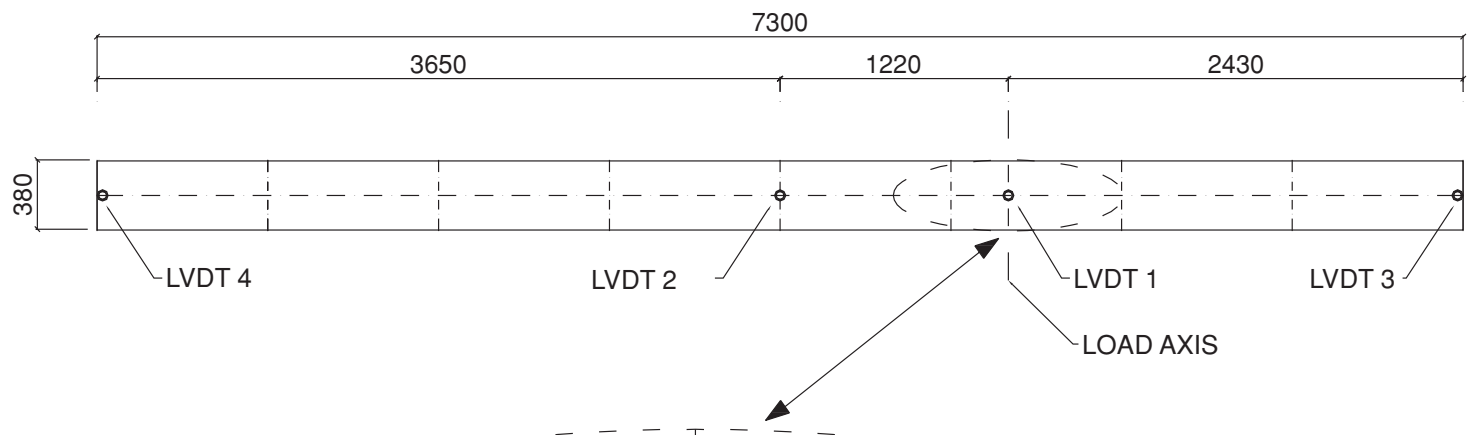

ENLARGEMENT x 5

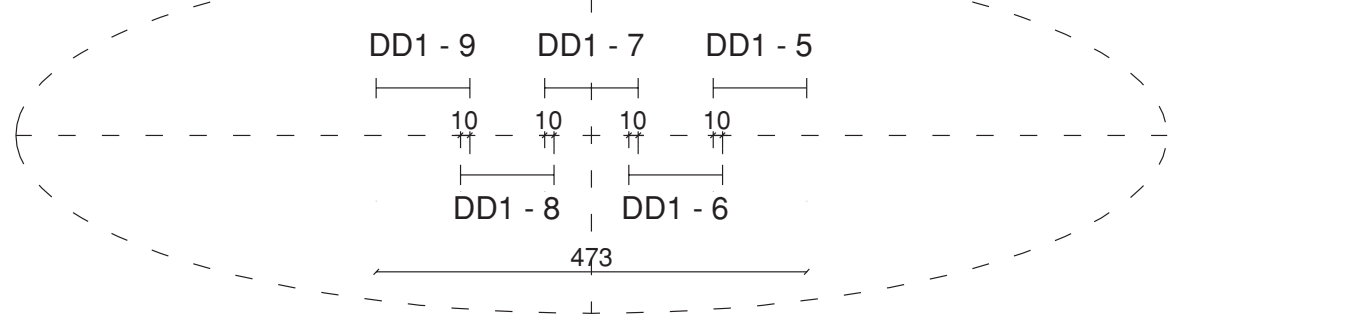

Fig. 2. Plan and elevation views showing accelerometer, excitation locations, and instrument setup (dimensions in mm). 


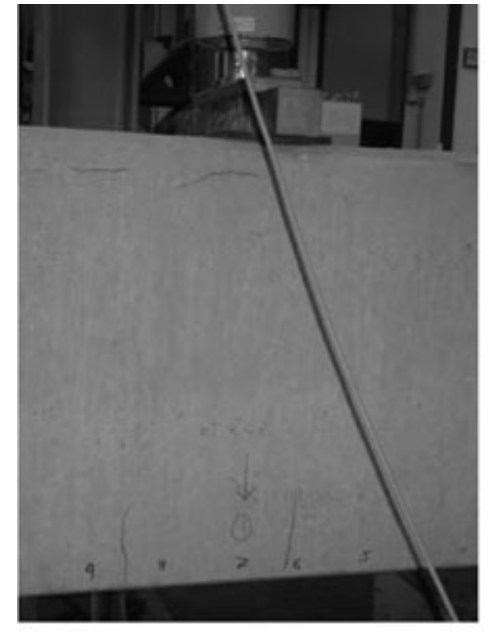

(a)

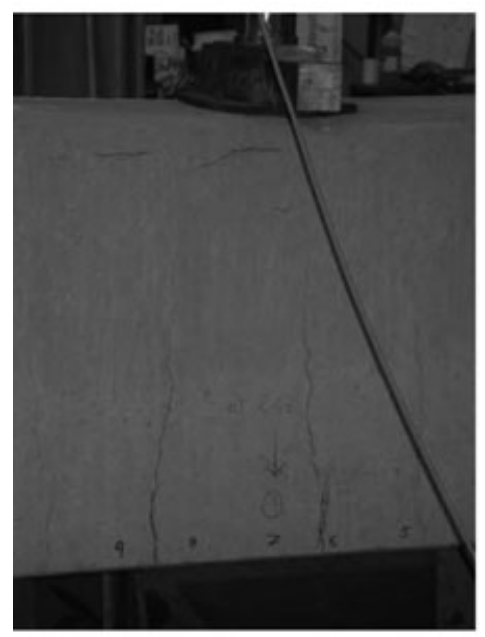

(c)

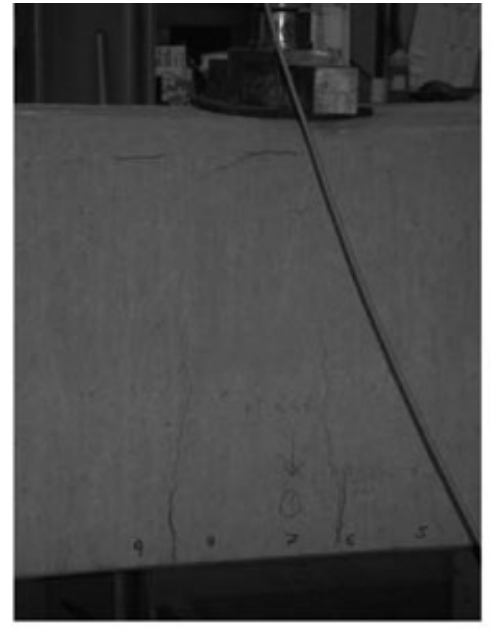

(b)

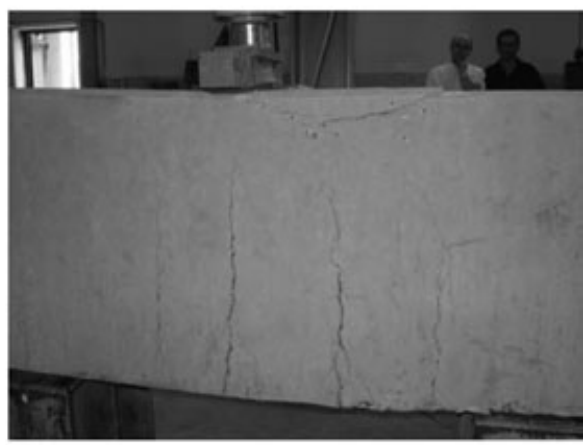

(d)

Fig. 3. Progressive cracks opening at increasing load (beam A [D3]).
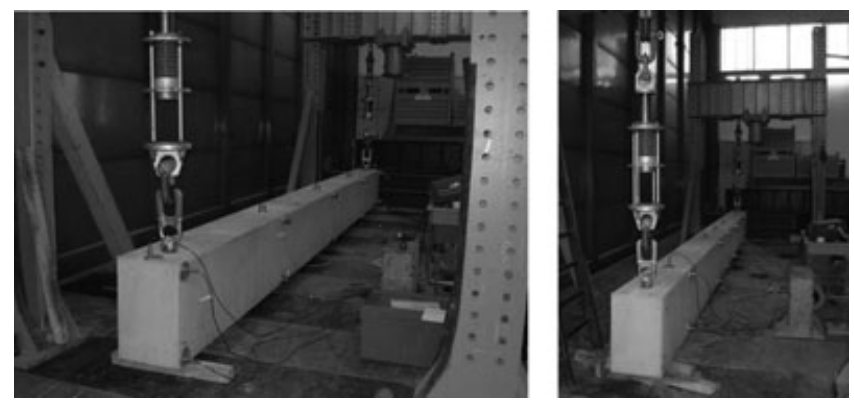

Fig. 4. Accelerometers in the first (left) and second (right) configurations.

The dynamic exciting force was hand generated by means of an impulse hammer, whose tip was chosen to generate a free decay response containing frequency components up to $250 \mathrm{~Hz}$. Dynamic forces were redun- dantly applied at four points (two at mid-span and two at the end section) to excite all symmetric and antisymmetric vertical bending and torsional modes. The positions of the excitation were represented by the black arrows in Figures 5 and 6 . The exciting forces were applied perpendicular to the beam axis in the $\mathrm{X}$ (transverse) and $\mathrm{Y}$ (vertical) direction. Figure 7a shows the time history of a typical impulsive loading, whereas Figure $7 \mathrm{~b}$ shows a typical response acceleration.

To improve the measurement accuracy and identify as many modal shapes as possible, the accelerometers were set up in two different acquisition configurations without changing the position of the three accelerometers at mid-span. Figures 5 and 6 show the two configurations of the accelerometers represented by numbered circles. As a result, for each sensor configuration, a total of 16 responses are recorded including five vertical 

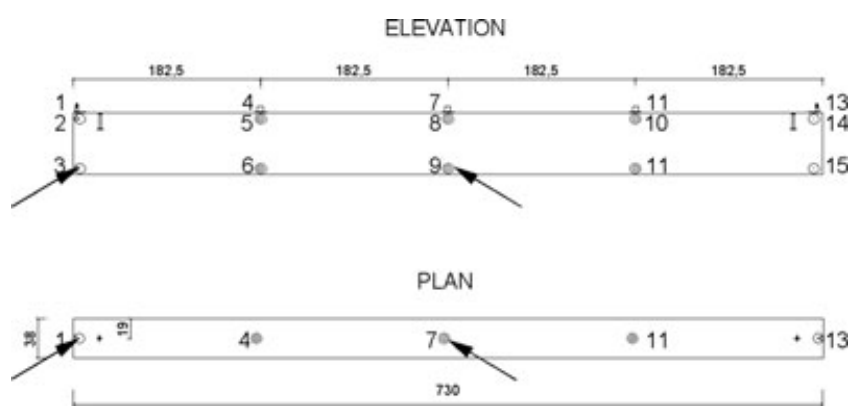

Fig. 5. Setup of the accelerometers in the first configuration.

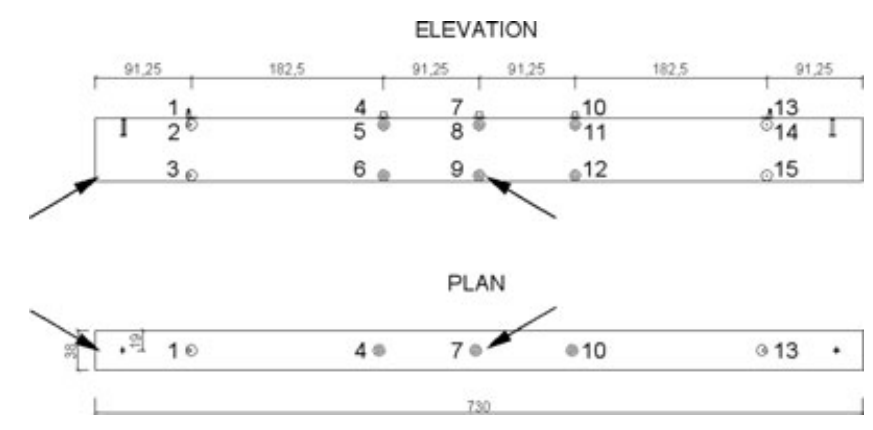

Fig. 6. Setup of the accelerometers in the second configuration.

accelerations (one at the mid-span as reference), 10 horizontal accelerations (two at mid-span as reference), and the input load.

In total, 15,630 time histories were acquired for the dynamic test. For each beam, time histories were acquired under two sensor configurations, four damage levels, and four impulse excitation positions. Each excitation was repeated at least 10 times. The sampling frequency of the data acquisition was $f_{s}=2,000 \mathrm{~Hz}$. For each time history, 16,384 $\left(=2^{14}\right)$ data points were used, so the acquisition time $t_{a}$ was 8.192 seconds.

Time histories - Beam A - 1st configuration - D0 - HAMMER

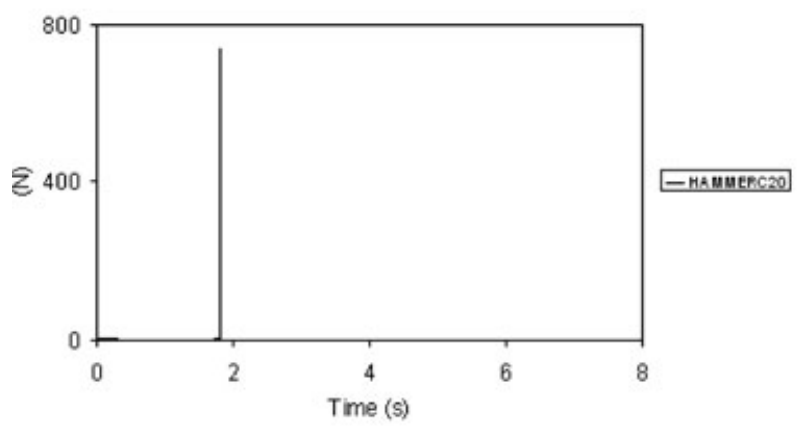

(a)
The first part of the analysis concerned the extraction of the classical modal parameters including the natural frequencies and mode shapes of the PRC beams in four different damage states: undamaged state D0, decompression D1, first crack D2, and failure D3 that reached the maximum compressive strength of concrete. The methods for extracting modal parameters can be found extensively in literature (e.g., Ren and De Roeck, 2002a, 2002b; Kim and Stubbs, 2003). More details on these tests can be found in Franchetti (2004) and Franchetti et al. (2004). This article focuses on damping analysis for damage detection.

\section{MODAL DAMPING IDENTIFICATION}

Based on the previous research on PRC elements (Sonda, 1999; Zonta, 2000) in which modal parameters were extracted by different techniques and compared, this study adopts the multi-degree-of-freedom (MDOF) curve fitting and the Hilbert transform methods. Modal parameters were, first, identified by the multi-input multi-output (MIMO) curve fitting of the experimental frequency response functions (FRFs). In particular, a visual program $\left(\right.$ Labview $\left.^{\mathrm{TM}}, 2000\right)$ was used (Lanaro, 2002), which is capable of considering FRFs of a MDOF system simultaneously for different impulse forces (Sonda, 1999).

The damping results identified for the $\mathrm{Y}$ (vertical) bending and torsional modes for beam $\mathrm{C}$ are reported in Table 4 and in Figure 8, together with the corresponding natural frequencies. The damping results for the $\mathrm{X}$ (horizontal) bending modes appeared to be less sensitive to damage in comparison to the damping extracted from fitting of vertical and torsional modes. As an example, the identification results for beam $\mathrm{C}$ are presented in Table 5 and Figure 9. The modal

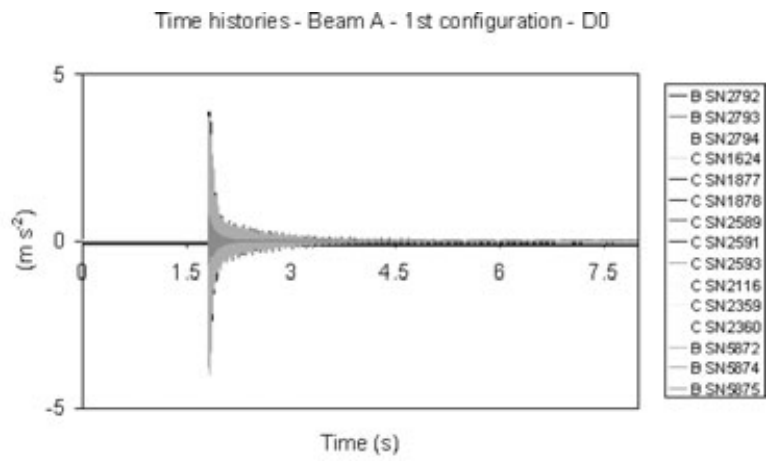

(b)

Fig. 7. Typical impulse loading time history (a) and acceleration responses time histories (b). 
Table 4

Summary of modal damping for Y-bending modes and torsional mode of beam $\mathrm{C}$

\begin{tabular}{|c|c|c|c|c|c|c|c|c|}
\hline \multirow[b]{2}{*}{ Beam C } & \multirow[b]{2}{*}{$\begin{array}{c}\text { Natural } \\
\text { frequencies }(H z)\end{array}$} & \multicolumn{7}{|c|}{ Damage state } \\
\hline & & $\begin{array}{c}\text { Do } \\
\text { Damping } \\
\text { ratio } \xi(\%)\end{array}$ & $\begin{array}{c}\text { Damping } \\
\text { ratio } \xi(\%)\end{array}$ & $\begin{array}{c}\text { Increase } \\
(\%)\end{array}$ & $\begin{array}{c}\text { Damping } \\
\text { ratio } \xi(\%)\end{array}$ & $\begin{array}{c}\text { Increase } \\
(\%)\end{array}$ & $\begin{array}{c}\text { Damping } \\
\text { ratio } \xi(\%)\end{array}$ & $\begin{array}{c}\text { Increase } \\
(\%)\end{array}$ \\
\hline First Y-bending mode & 44.89 & 0.3642 & 0.3821 & 4.91 & 0.4101 & 12.60 & 0.4284 & 17.63 \\
\hline Second Y-bending mode & 110.50 & 0.8593 & 0.7879 & -8.3 & 0.6203 & -27.81 & 1.0485 & 22.01 \\
\hline First torsional mode & 142.33 & 0.2776 & 0.3684 & 32.71 & 0.3573 & 28.71 & 0.5523 & 98.96 \\
\hline
\end{tabular}

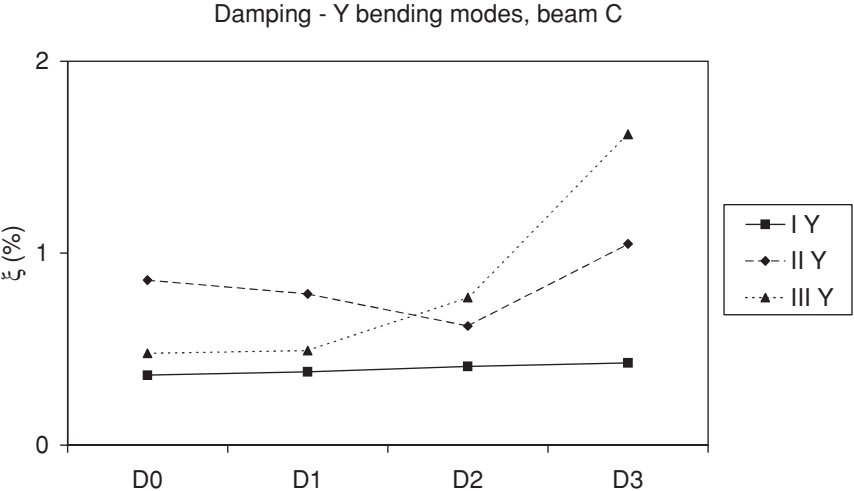

(a)

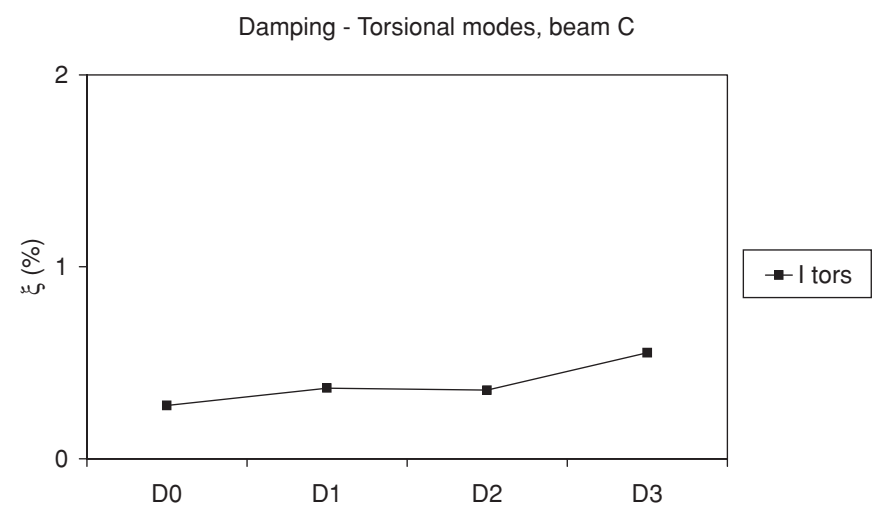

(b)

Fig. 8. Modal damping trend, beam C: Y-bending modes (a) and I torsional mode (b).

Table 5

Summary of modal damping for X-bending modes of beam C

\begin{tabular}{|c|c|c|c|c|c|c|c|c|}
\hline \multirow[b]{3}{*}{ Beam C } & \multirow[b]{3}{*}{$\begin{array}{c}\text { Natural } \\
\text { frequencies }(\mathrm{Hz})\end{array}$} & \multicolumn{7}{|c|}{ Damage level } \\
\hline & & \multirow{2}{*}{$\begin{array}{c}D 0 \\
\text { Damping } \\
\text { rate } \xi(\%)\end{array}$} & \multicolumn{2}{|c|}{ D1 } & \multicolumn{2}{|c|}{$D 2$} & \multicolumn{2}{|c|}{ D3 } \\
\hline & & & $\begin{array}{l}\text { Damping } \\
\text { rate } \xi(\%)\end{array}$ & $\begin{array}{c}\text { Increase } \\
(\%)\end{array}$ & $\begin{array}{l}\text { Damping } \\
\text { rate } \xi(\%)\end{array}$ & $\begin{array}{l}\text { Increase } \\
(\%)\end{array}$ & $\begin{array}{l}\text { Damping } \\
\text { rate } \xi(\%)\end{array}$ & $\begin{array}{c}\text { Increase } \\
(\%)\end{array}$ \\
\hline First X-bending mode & 28.73 & 0.3282 & 0.2838 & -13.53 & 0.2810 & -14.38 & 0.3889 & 18.49 \\
\hline Second X-bending mode & 77.53 & 0.1000 & 0.5728 & 472.8 & 0.5312 & 431.20 & 0.500 & 400.00 \\
\hline Third X-bending mode & 149.80 & 0.3776 & 0.3753 & -0.61 & 0.3823 & 1.24 & 0.1250 & -66.90 \\
\hline
\end{tabular}

damping ratios identified by MIMO curve fitting of the FRFs apparently were sensitive to damage state D3 only.

An alternative modal extraction method was applied, which consists of evaluating the decay in the oscillation amplitude by using modal filtering and the Hilbert transform (Feldman, 1994, 1997; Worden and Tomlinson, 2001). The method can therefore be used, in the narrow frequency bandwidth, for each of the singledegree-of-freedom (SDOF) systems. After uncoupling the other degrees of freedom components by applying the band-pass filter, and short-time Fourier transform, a new signal representing one degree of freedom, referred to as the complex analytical signal, was generated. It is noted that this method can be used only if frequencies are uncoupled and the behavior is linear.

The procedure was implemented in a visual programming platform (Franchetti, 2004). Because the first mode (rigid body) was sufficiently uncoupled due to the highly flexible supporting springs, band-pass filtering was applied only to separate the elastic models of the beam.

From the newly generated free decay signal representing each degree of freedom, damping coefficient $\xi$ 
Damping - $\mathrm{X}$ bending modes, beam $\mathrm{C}$

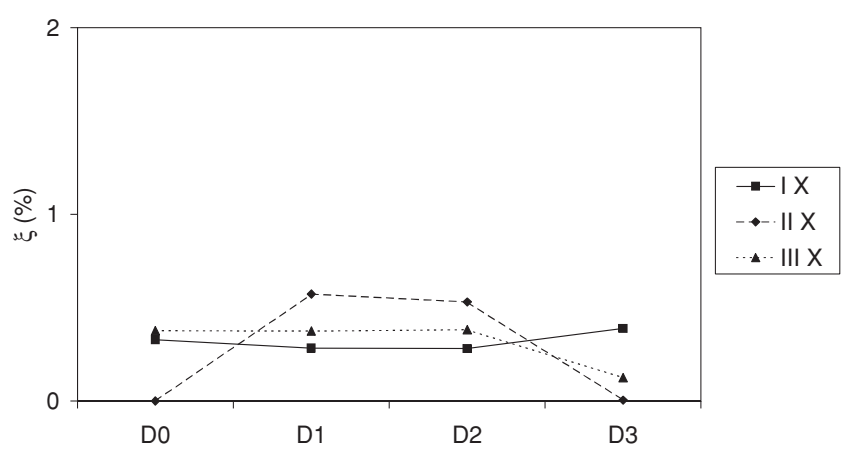

Fig. 9. Modal damping trend (X-bending modes, beam C).

was calculated by exponential fit with the analytical signal given by

$$
g(t)=\beta e^{-\xi \omega t}
$$

where $t$ is the time and $\beta$ is a constant. The frequency of the particular individual mode $\omega$ is directly obtained from the phase (Franchetti, 2004).

Here, linear viscous damping was assumed for both damaged and undamaged beams. In other words, the amplitude of the response to the impulsive excitation follows the exponential decay. Modal damping ratios vary greatly after concrete cracking, particularly for the bending modes. As shown in Table 6, the two different techniques, the MIMO curve fitting and the Hilbert transform, lead to slightly different damping values.

From the damping identification results, it is observed that modal damping ratios increased significantly when the specimens were damaged. In particular, the damping of the Y-bending mode more than doubled when the specimen experienced state D3 damage.

On the other hand, as the variation of modal damping can be interpreted as a variation of the energy dissipative mechanism in the zone of the cracks, the viscous equivalent modal damping may not be a reasonable approximation. In fact, there are many causes of energy dissipation such as hysteresis loops that occur in the postcracking compression state (CEB
210, 1991; Alleruzzo et al., 1997), and the friction between steel rebar and concrete (Dieterle and Bachmann, 1981). Therefore, a more detailed study of the energy dissipative mechanisms was further investigated in this study, as presented below.

\section{DAMPING BEHAVIOR OF REINFORCED CONCRETE BEAMS}

Material damping in reinforced concrete elements in the quasi-elastic range (without yielding of reinforcement) shows special features due mainly to cracking (Mahrenholtz and Bachmann, 1991). With no cracking in an ordinary or prestressed concrete structure, material damping can be assumed as pure viscous damping. The damping ratio is essentially constant and is equal to $0.7-10 \%$ for uncracked reinforced concrete, and $0.4 \%$ to $0.7 \%$ for uncracked prestressed concrete (Swamy, 1971; Dieterle and Bachmann, 1981; Mahrenholtz and Bachmann, 1991).

In a cracked state in reinforced concrete elements, damping occurs due to two kinds of energy dissipation mechanism (Mahrenholtz and Bachmann, 1991):

- nearly pure viscous damping in concrete in the uncracked compression zone; and

- nearly pure friction damping due to friction between concrete and reinforcing steel in the cracked tension zone.

For ordinary reinforced concrete, interpretative models of the damping mechanism exist (Dieterle and Bachmann, 1981). The equivalent damping of a cracked beam results from the simple sum, in terms of energy, of the viscous damping and friction damping.

In particular, it was observed that damping strongly depends on the stress intensity for general concrete structures. Damping is low for a low stress intensity corresponding to an uncracked state. The equivalent damping ratio increases during crack formation; damping is high in the final crack state, but still with relatively low stress intensity. After cracking, with further increase of the stress intensity, damping ratio decreases rapidly to

Table 6

Identified damping ratios for Y-bending mode of beam $\mathrm{C}$

\begin{tabular}{|c|c|c|c|c|c|c|c|c|}
\hline Beam $C$ & \multicolumn{8}{|c|}{ Damping rate $\xi(\%)$} \\
\hline First Y-bending mode & 0.3642 & 0.3821 & 0.4101 & 0.4284 & 0.4268 & 0.4385 & 0.4111 & 0.5138 \\
\hline Second Y-bending mode & 0.8593 & 0.7879 & 0.6203 & 1.0485 & 1.056 & n. a. & n. a. & n. a. \\
\hline
\end{tabular}



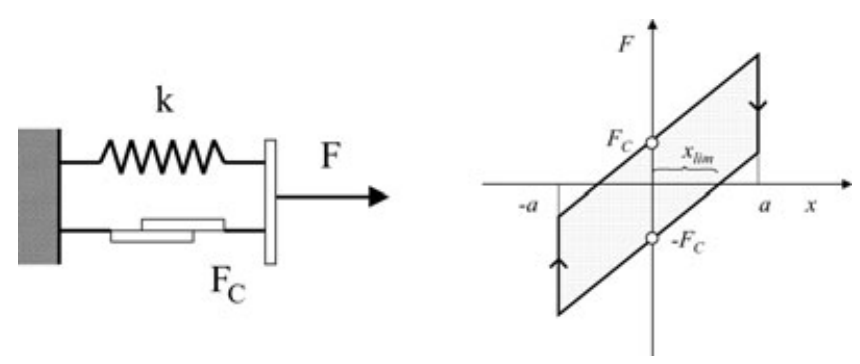

Fig. 10. Hysteretic dashpot (left) and restoring force (right) relative to an oscillator with Coulomb friction damping.
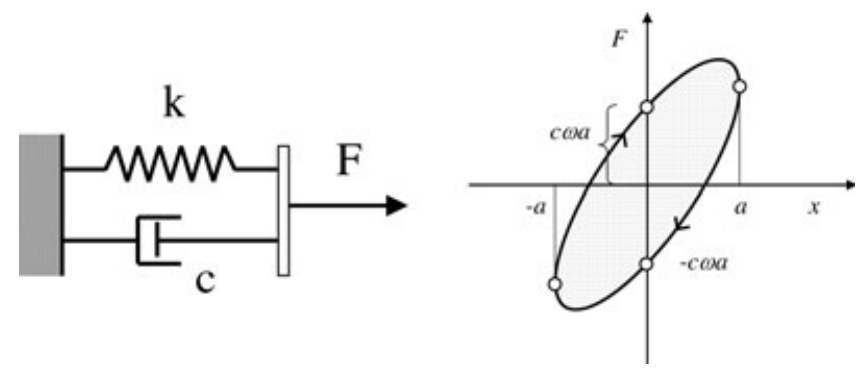

Fig. 11. Viscous dashpot (left) and restoring force relative to an oscillator viscous damped (right).

values that can be smaller than in the initial uncracked state (Mahrenholtz and Bachmann, 1991).

However, this is not the case in PRC, as proved in the following sections. In fact, when the load is removed, the crack closes and the section is compressed. Therefore, the reinforced concrete model (Dieterle and Bachmann, 1981) cannot be applied to PRC elements, especially where there are stresses under decompression, because the model is based on the fundamental hypothesis that, in the cracked section, the tension is only transmitted by the steel.

\subsection{SDOF oscillator with Coulomb friction}

The combined model with a purely viscous damping and purely friction models was proposed in Modena

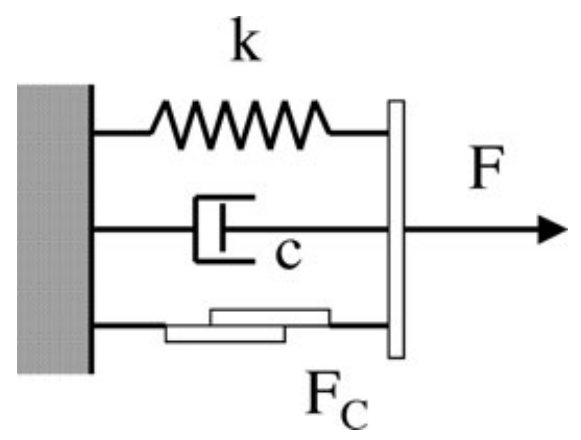

Fig. 13. Combined damping model.

et al. (1999), Sonda (1999), and Zonta (2000). The presence of the friction in an SDOF system can be represented by a hysteretic dashpot as shown in Figure 10. The Coulomb friction force $F$ has a constant amplitude $F_{C}$ and its sign depends only on the direction of motion:

$$
F=-F_{C} \frac{\dot{x}}{|\dot{x}|}
$$

where $\dot{x}$ is the velocity of motion. Figure 10 also shows a typical hysteretic cycle for a friction-damped oscillator.

On the other hand, the presence of the pure viscous damping in an SDOF system can be represented by a viscous dashpot as shown in Figure 11. The free response of a Coulomb friction-damped oscillator and a viscously damped oscillator are depicted in Figure 12. The envelopes of the free responses are

$$
a(t)=a_{0}-\frac{2}{\pi} \omega \frac{F_{C}}{k} t \text { for Coulomb friction damping }
$$

$$
a(t)=a_{0} e^{-\xi \cdot \omega \cdot t} \quad \text { for viscous damping }
$$

where $a_{0}$ is the initial amplitude and $\omega$ is the circular frequency.

The damping behavior of a cracked RC structure can be described by a friction-viscous combined damping model, as presented in Figure 13. Therefore, the equation of motion of the combined system becomes
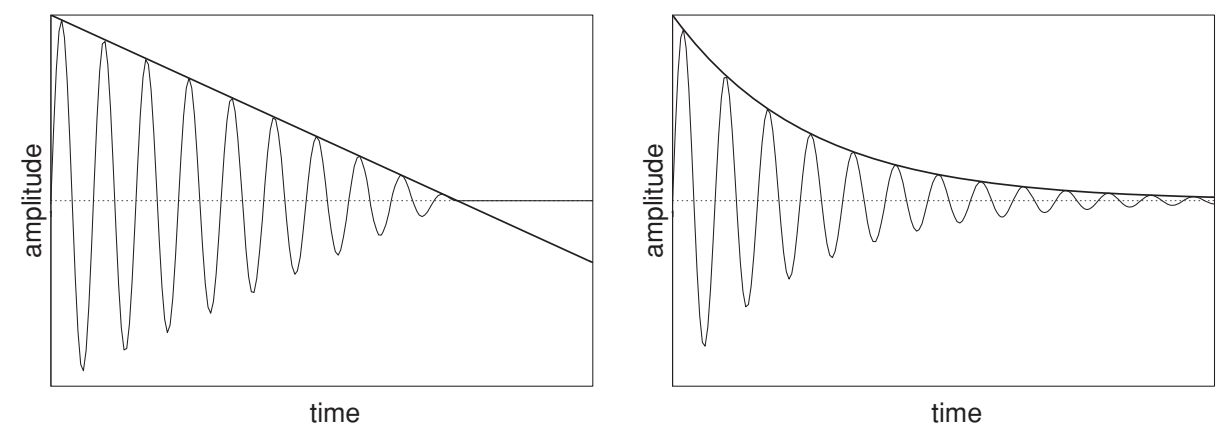

Fig. 12. Free response of a Coulomb friction-damped oscillator (left) and purely viscous-damped oscillator (right). 


$$
m \cdot \ddot{x}+c \cdot \dot{x}+F_{C} \frac{\dot{x}}{|\dot{x}|}+k \cdot x=0
$$

or mass normalized as

$$
\ddot{x}+2 \omega \xi \dot{x}+\omega^{2} x_{\lim } \frac{\dot{x}}{|\dot{x}|}+\omega^{2} x=0
$$

where $m$ is the mass, $k$ is the stiffness, $c$ is the viscous damping coefficient, and the limit displacement is defined as

$$
x_{\lim }=\frac{F_{C}}{k}
$$

as $x_{\lim }$ represents the limit displacement in the static equilibrium.

An exact solution to this problem can be found by a step-by-step integration of the equation of motion. A sufficiently accurate approximation for practical purposes was obtained (Modena et al., 1999; Sonda, 1999; Zonta, 2000) by calculating the energy dissipated by the friction force $\Delta E_{f_{r i c t}}$ and viscous damping force $\Delta E_{v i s c}$ and equating these to the loss of the total mechanical energy $\Delta E_{m}$ (Den Hartog, 1985):

$$
\Delta E_{m}=\Delta E_{v i s c}+\Delta E_{\text {frict }}
$$

The energy loss was computed by assuming a sinusoidal response:

$$
x(t)=a(t) \sin (\omega t)
$$

With harmonic motion, the large elastic and inertia forces are harmonic and only the small damping force causes a deviation from harmonic motion.

The dissipated energy per cycle is

$$
\begin{gathered}
\Delta E_{v i s c}=\int-F(\dot{x}) d x=\int_{0}^{T} c \dot{x} \frac{d x}{d t} d t=\pi c \omega a_{0}^{2} \\
\Delta E_{\text {frict }}=\int-F(\dot{x}) d x=4 F_{C} a_{0}
\end{gathered}
$$

Therefore, from Equation (6), the amplitude of the oscillation, at an arbitrary time $t$, can be obtained as (Modena et al., 1999; Sonda, 1999; Zonta, 2000)

$$
a(t)=\left(a_{0}+a_{f}\right) \cdot e^{-\xi \cdot \omega \cdot t}-a_{f}
$$

where $a_{0}$ is the initial amplitude and

$$
a_{f}=\frac{2}{\pi \cdot \xi} \cdot x_{\lim }
$$

Equation (12) shows how the amplitude decay in the combined damping model is still exponential, tending not to zero but to $-a_{f}$ as seen in Figure 14. The figure also shows the comparison of this approximated expression and the numerical solution of the exact differential equation.

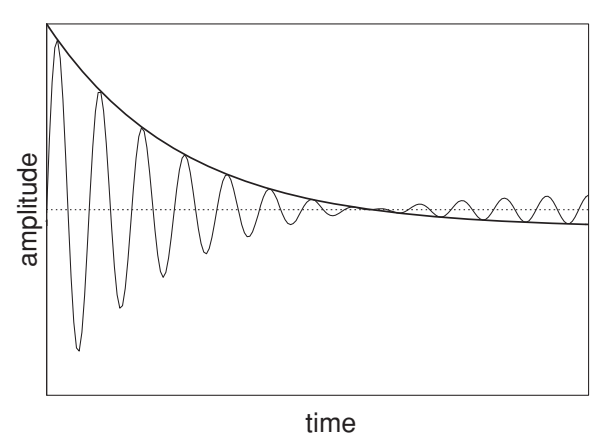

Fig. 14. Free vibration response of combined damped oscillator.

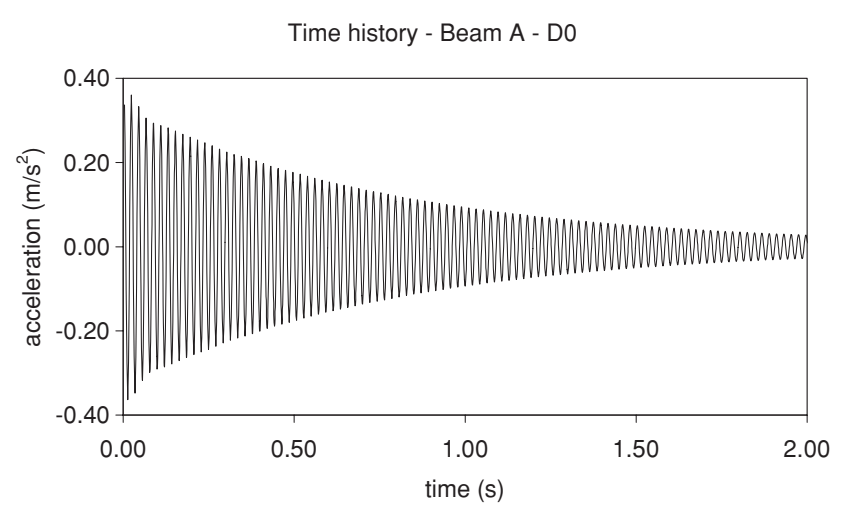

Fig. 15. Measured time history of free vibration of the undamaged beam A (D0).

\subsection{Comparison with experimental observations}

First, analytical responses of the free vibration of the beams were computed using the pure viscous damping model and compared with the experimental results. The best fitting of the analytical amplitudes to the experimental ones was performed to determine the optimal damping ratio $\xi=0.00414$. Using the identified damping ratio, analytical free vibration responses were computed. Figures 15 and 16, respectively, show the measured free vibration time history, and the comparison of the analytical and experimental amplitude envelopes, in the first Y-bending frequency of the vertical acceleration at the mid-span of undamaged beam A (under D0). Similar results are shown in Figures 17 and 18 for the damaged beam A (under D3) in which the optimal damping ratio was identified as $\xi=0.00601$.

It is observed that the pure viscous damping model, that is, the exponential fitting, describes the undamaged beam (D0) very well, as shown in Figure 16. However, for the damaged beam, the viscous damping model is rather imprecise as demonstrated in Figure 18. Furthermore, in the logarithmic scale, the measured free vibration amplitude envelope is convex for the 


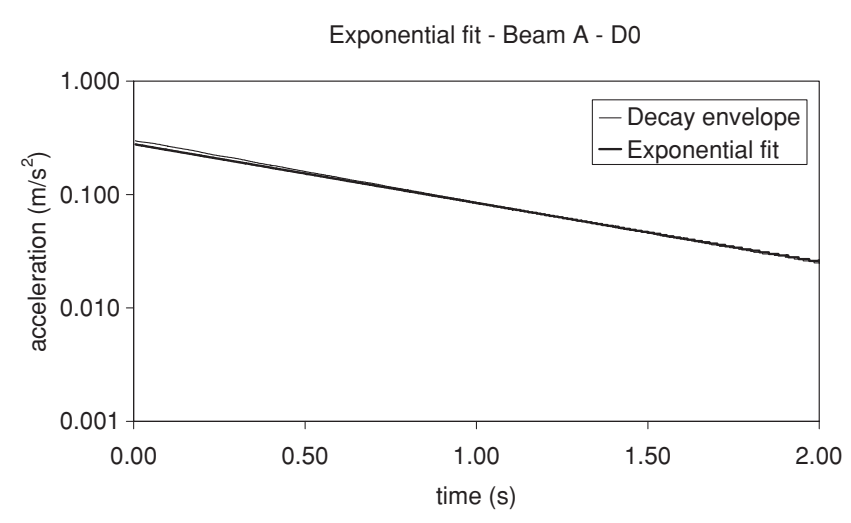

Fig. 16. Exponential fit of free vibration amplitude.

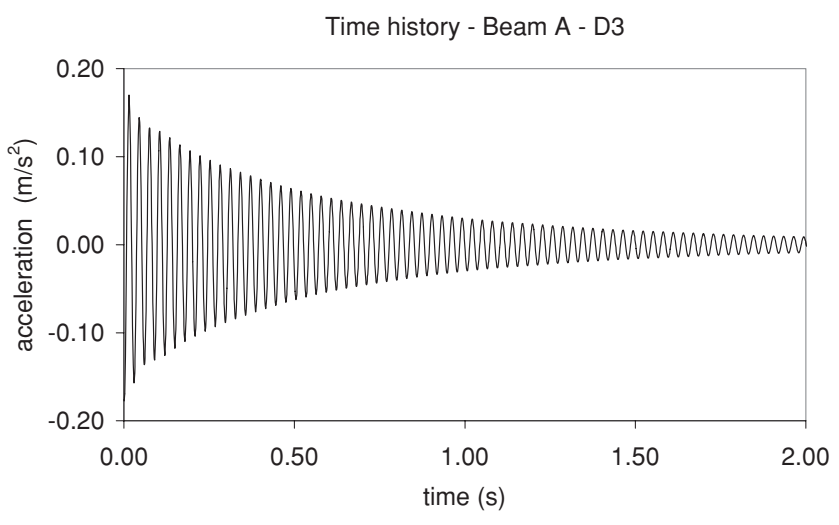

Fig. 17. Measured time history of free vibration of the damaged beam A (D3).

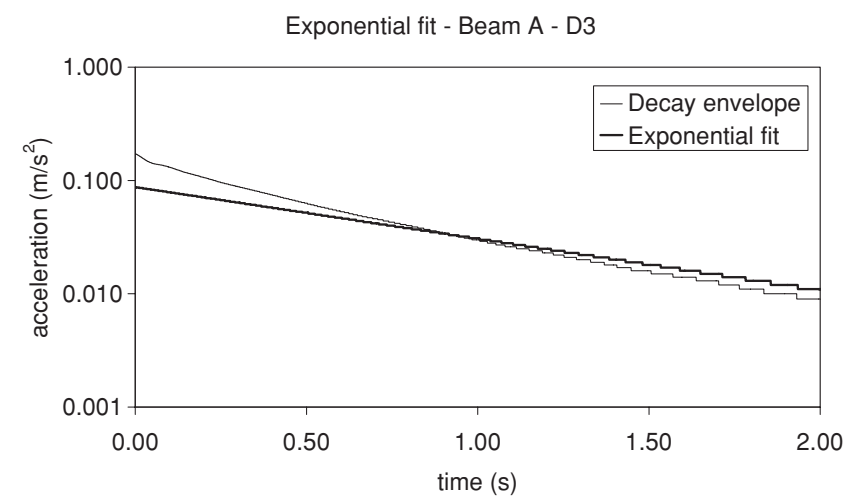

Fig. 18. Exponential fit of free vibration amplitude.

damaged beam, whereas the exponential fit is a straight line, and even the viscous-friction combined model Equation (12) is concave, not convex. Therefore, the combined viscous-friction damping model is not capable of adequately modeling the damaged beam either. Similar observations were made for all the three beams tested in this study. Therefore, an alternative friction damping model was proposed in this study for describ-

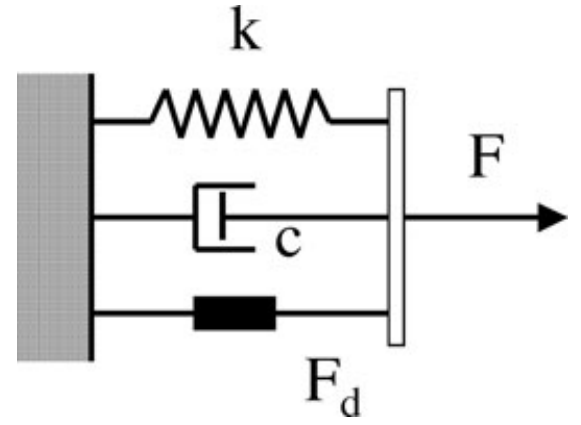

Fig. 19. Combined damping model.

ing the energy dissipation mechanism in damaged PRC beams.

\subsection{Proposed quadratic damping model}

The proposed model combines pure viscous damping with a polynomial damping, as illustrated in Figure 19. The most common form of a polynomial damping force is quadratic:

$$
F_{d}=-d \cdot \dot{x} \cdot|\dot{x}|
$$

where $d$ is constant and the absolute value of the velocity is introduced to ensure that the force is always opposed to the velocity. This damping model is commonly used in fluid dynamics, when describing fluid flowing through an orifice or around a slender member. The free vibration responses and the damping forces computed using a pure quadratic damping model, in comparison with those using a quadratic and viscous combined damping model, are respectively shown in Figures 20 and 21.

Similar to Equation (9), the dissipated energy per cycle is assumed as

$$
\Delta E_{\text {quadr }}=\int-F_{d}(\dot{x}) d x=\int_{0}^{T} d \dot{x}|\dot{x}| \frac{d x}{d t} d t=\frac{8}{3} d a_{0}^{3} \omega^{2}
$$

The equation of motion of the quadratic and viscous combined system becomes

$$
m \ddot{x}+c \dot{x}+d \dot{x}|\dot{x}|+k x=0
$$

The loss of mechanical energy per cycle must be equal to the total dissipated energy, as shown in Equation (8). The loss of mechanical energy per cycle is (this time considering $a$ instead of $a_{0}$, because the balance is not yet integrated in time)

$$
\frac{1}{2} k a^{2}-\frac{1}{2} k(a+\Delta a)^{2}=-k a \Delta a-\frac{1}{2} k(\Delta a)^{2} \cong-k a \Delta a
$$



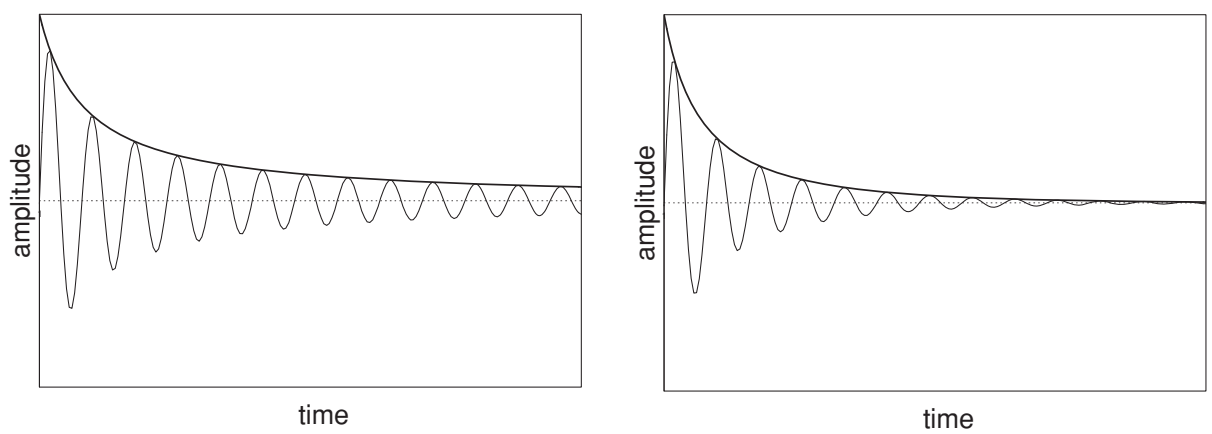

Fig. 20. Free vibration responses of a quadratic-damped (left) and a combined quadratic viscous-damped (right) oscillator.
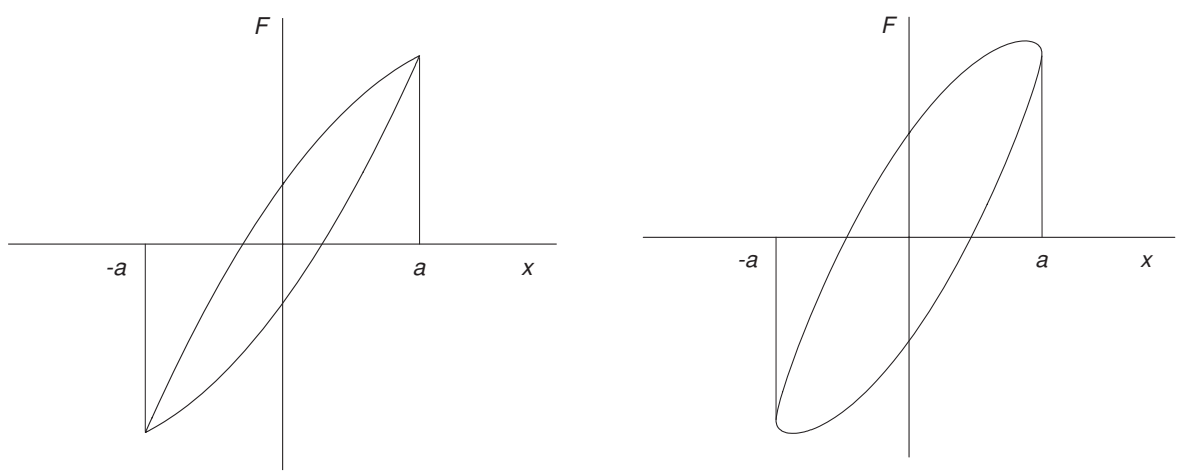

Fig. 21. Damping force of a quadratic-damped (left) and a combined quadratic viscous-damped (right) oscillator.

where the amplitude of oscillation $a>0$ and its variation $\Delta a<0$ are functions of time. In this case, the expression becomes

$$
\begin{aligned}
-k a \Delta a & =\pi c \omega a^{2}+\frac{8}{3} d a^{3} \omega^{2} \Rightarrow-k \Delta a \\
& =\pi c \omega a+\frac{8}{3} d a^{2} \omega^{2}
\end{aligned}
$$

This equation can be normalized as follows

$$
-\omega^{2} \Delta a=\pi 2 \xi \omega^{2} a+\frac{8}{3} \delta a^{2} \omega^{2} \Rightarrow-\Delta a=\pi 2 \xi a+\frac{8}{3} \delta a^{2}
$$

where

$$
\delta=\frac{d}{m}
$$

is defined as quadratic damping factor.

Dividing each member for $\Delta t=T=2 \pi / \omega$, one can obtain the same balance in terms of power:

$$
-\frac{\Delta a}{\Delta t}=\xi \omega a+\frac{4}{3 \pi} \delta \omega a^{2}
$$

Taking the limit, the following relation is derived

$$
-\frac{d a}{d t}=\xi \omega a+\frac{4}{3 \pi} \delta \omega a^{2}
$$

Defining

$$
\begin{gathered}
\xi \omega=c_{1} \\
\frac{4}{3 \pi} \delta \omega=c_{2}
\end{gathered}
$$

the previous expression then simplifies to

$$
\frac{d a}{d t}=-\left(\xi \omega a+\frac{4}{3 \pi} \delta \omega a^{2}\right)=-a\left(c_{1}+c_{2} a\right)
$$

By separating the variables

$$
\frac{d a}{c_{1} a+c_{2} a^{2}}=-d t
$$

and integrating both of the terms

$$
\begin{gathered}
\int_{a_{0}}^{a} \frac{d a}{c_{1} a+c_{2} a^{2}}=-\int_{0}^{t} d t \\
{\left.\left[\log \left(\frac{a}{c_{1}+c_{2} a}\right)\right]\right|_{a_{0}} ^{a}=-c_{1} t} \\
\frac{a}{c_{1}+c_{2} a} \frac{c_{1}+c_{2} a_{0}}{a_{0}}=e^{-c_{1} t}
\end{gathered}
$$

and, finally

$$
a(t)=\frac{\left(a_{0} c_{1}\right) \cdot e^{-c_{1} \cdot t}}{c_{1}+a_{0} c_{2}\left(1-e^{-c_{1} \cdot t}\right)}
$$


If $c_{2}=0$ (with pure viscous damping) the exact solution is

$$
a(t)=a_{0} \cdot e^{-c_{1} \cdot t}=a_{0} \cdot e^{-\xi \omega t}
$$

The proposed model deals with quadratic damping. However, the mathematical expression for nonlinear damping could be substituted by an equivalent one (e.g., $F_{d}=-d \cdot \dot{x}^{3}$ with obvious changes in the formulation).

\subsection{Experimental validation}

In general, the proposed combined damping model characterizes the energy dissipation by the two parameters: the viscous damping ratio $\xi$, and the quadratic damping factor $\delta$. They were identified from the best fitting of the measured free vibration amplitudes of the three beams, using Equation (30) with $c_{1}$ and $c_{2}$ as variables. It is referred to as nonlinear fitting, versus the exponential fitting as shown in Section 4.2. Furthermore, $\xi$ and $\delta$ can be identified using Equations (23) and (24).

A modal band-pass filter was used to process the measured free vibration signals to obtain a mono-frequency free vibration, as described earlier. The LevenbergMarquardt fitting method was applied to identify the optimal values of $c_{1}$ and $c_{2}$ in Labview ${ }^{\mathrm{TM}}$ (2000) and furthermore identify the viscous damping ratio $\xi$ and the quadratic damping factor $\delta$. Figures 22 and 23 show the best fitting between the analytical and the experimental free vibration amplitudes of beam A at mid-span in the vertical direction in the first Y-bending frequency under damage states D0 and D3. The optimal values are identified as $\xi=0.004124$ and $\delta=0.002730 / \mathrm{m}$ for the undamaged beam, and $\xi=0.004868$ and $\delta=0.1009 / \mathrm{m}$ for the damaged beam (D3). It is observed that the decay in the measured free vibration amplitude is modeled very well by Equation (30) for both the undamaged and the damaged states.

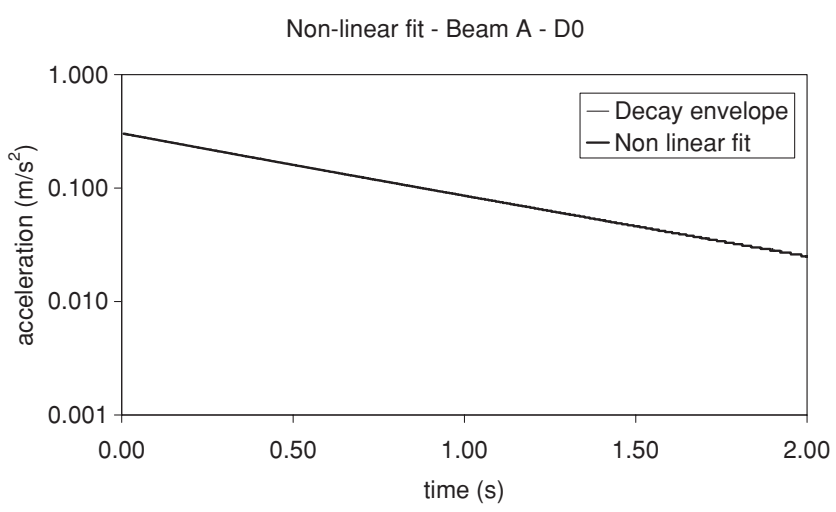

Fig. 22. Nonlinear fit of free vibration amplitude of beam A (D0).

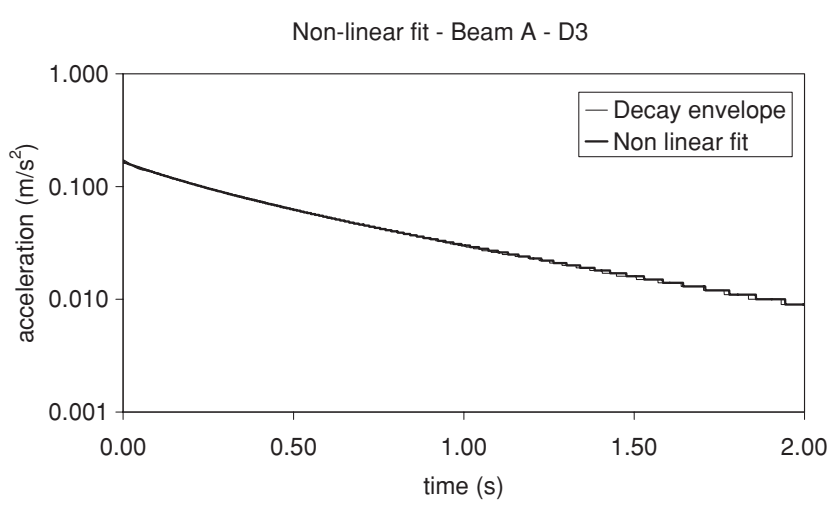

Fig. 23. Nonlinear fit of free vibration amplitude of beam A (D3).

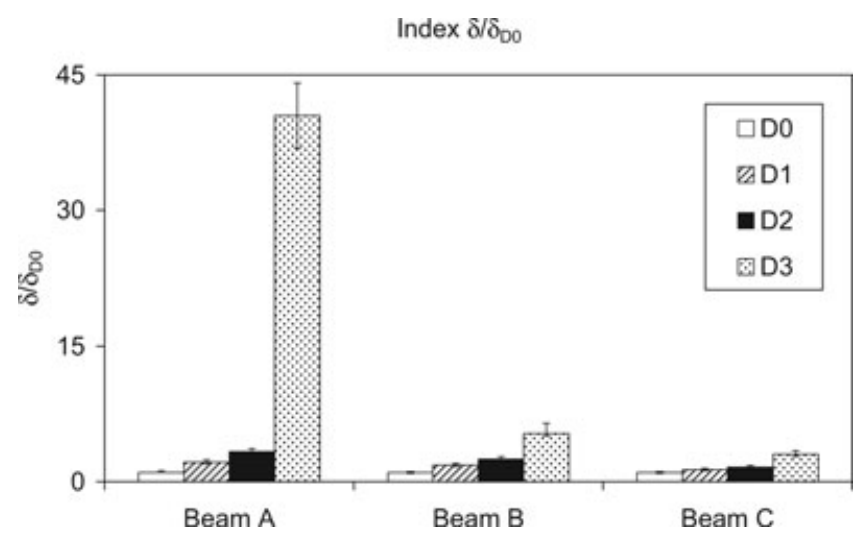

Fig. 24. Comparison of normalized quadratic damping factors under different damage states.

It is observed that the quadratic damping is insignificant in the undamaged beams but increases as the beams suffer damage. A correlation is observed between the damage state and the amount of the quadratic damping factor, as shown in Figure 24 and following. Figure 24 plots the quadratic damping factor under each damage state normalized by the undamaged factor for beams $\mathrm{A}, \mathrm{B}$, and $\mathrm{C}$. It is observed that the quadratic damping increases as the damage becomes more severe.

Figures 25-27 compare the value of the viscous damping ratio identified though best fitting of the pure viscous damping model (referred to as linear damping ratio herewith) with the values of $\xi$ and $\delta$ identified using the quadratic-viscous combined nonlinear model. It is observed that the damping ratio in the linear model does not change with the level of damage, whereas the quadratic damping factor in the combined nonlinear model correlates well with the level of damage.

Figure 28 shows that the amount of nonlinear damping increases as the damage level increases in different 
Beam A

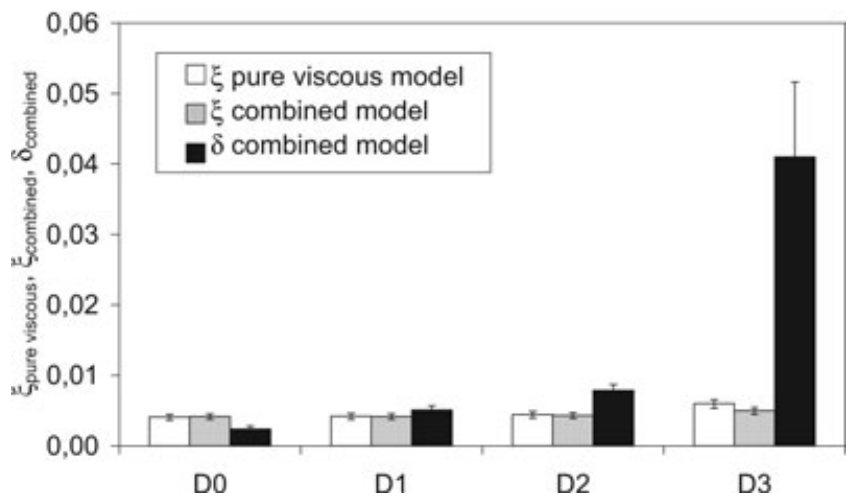

Fig. 25. Comparison between linear and nonlinear damping models for beam $\mathrm{A}$.

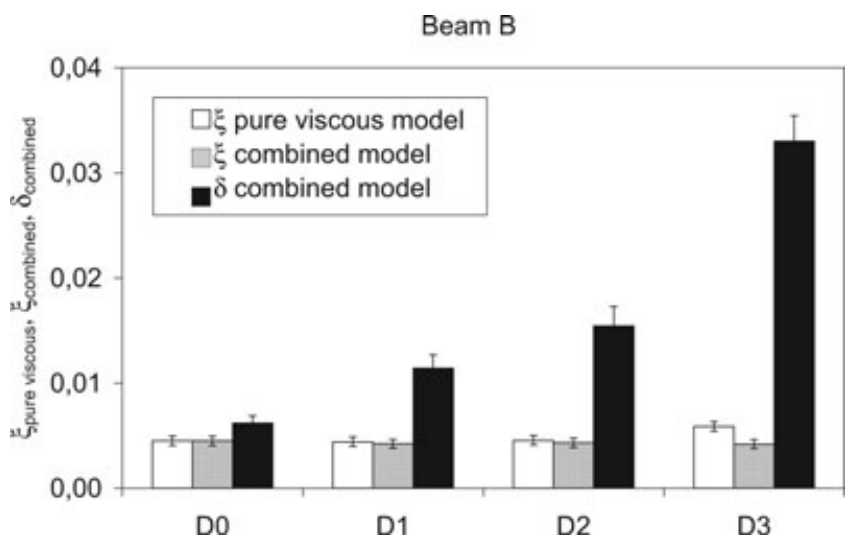

Fig. 26. Comparison between linear and nonlinear damping models for beam B.

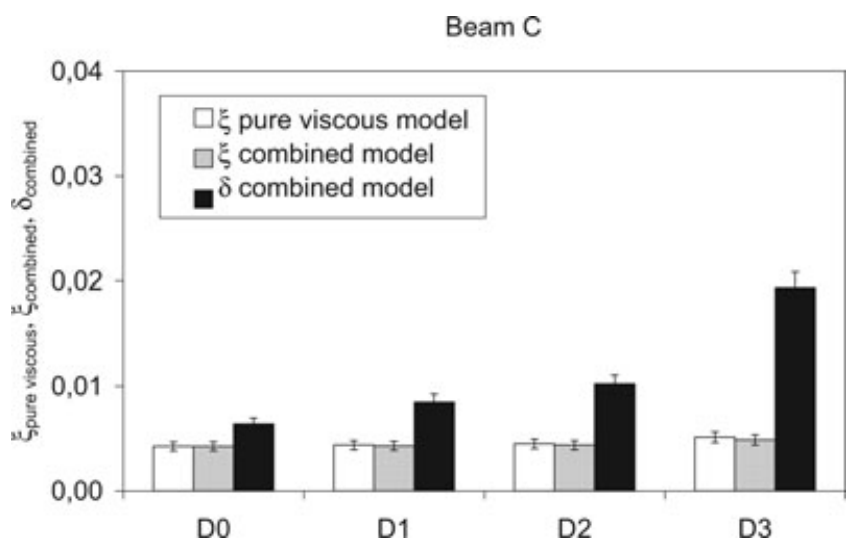

Fig. 27. Comparison between linear and nonlinear damping models for beam $\mathrm{C}$.

ways for the three different prestressing loads in the three beams.

It is clear that the introduction of damage produces a local variation of the energy dissipative mechanism that can be described by a notable increase in the value

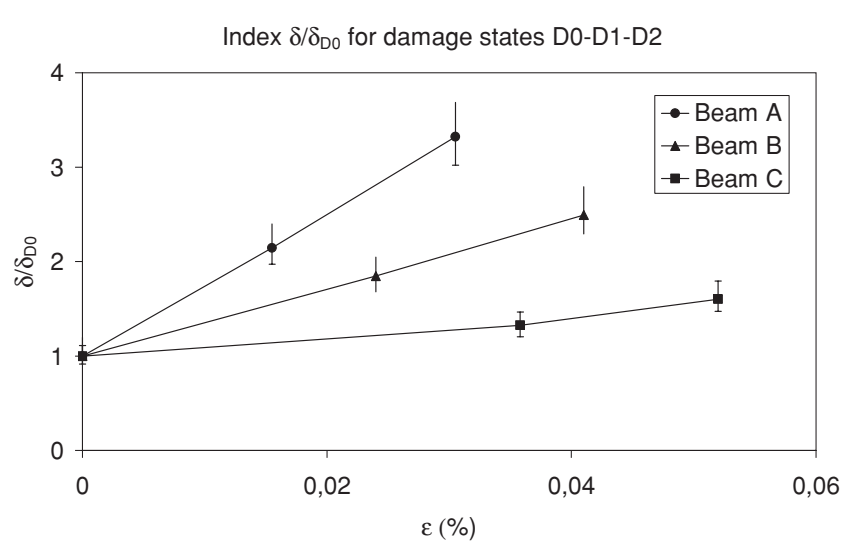

Fig. 28. Normalized quadratic damping factors for different damage states expressed by measured strains.

of such a parameter as $\delta$. The increase in the damage level appears to cause growth in internal microcracks or concrete-steel debonds resulting in increasing nonlinearity. The examination of such a mechanism at a micro level is beyond the scope of this article.

\section{CONCLUSIONS}

This article presents a damage identification method for precast PRC structural members based on damping analysis and identification of free vibration responses. Through an experimental study on the three PRC beam specimens damaged to different levels, it was demonstrated that a nonlinear quadratic damping factor proposed by the authors well represented the actual energy dissipation mechanism in PRC members associated with the different levels of damage. The quadratic damping factor is much more sensitive to the presence of damage than the viscous damping ratio, and thus can be effectively used for damage identification purposes.

The damping identification method presented in this article is particularly suited for quality control and assurance of PRC beams during their manufacturing process, because a free vibration test is easy to perform. The technique described in this article is based on the analysis of a free vibration signal, which limits its field application because of the difficulty in obtaining a free vibration response of a structure. The authors are working to expand this method for in situ damage detection of concrete structures based on ambient vibration measurement.

\section{REFERENCES}

Adeli, H. \& Jiang, X. (2006), Dynamic fuzzy wavelet neural network model for structural system identification, Journal of Structural Engineering, ASCE, 132(1), 102-11. 
Alleruzzo, S., Cangiano, S. \& Plizzari, G. A. (1997), Sul Comportamento del Calcestruzzo Fessurato sottoposto a Carichi Ciclici, Studi e Ricerche, 18, 1-30.

Carden, E. P. \& Brownjohn, J. M. W. (2008), Fuzzy clustering of stability diagrams for vibration-based structural health monitoring, Computer-Aided Civil and Infrastructure Engineering, 23(5), 360-72.

Cawley, P. \& Adams, R. D. (1979), The location of defects in structures from measurements of natural frequencies, Journal of Strain Analysis, 14(2), 49-57.

CEB 210. (1991), Behavior and Analysis of Reinforced Concrete Structures Under Alternate Actions Inducing Inelastic Response-Chapter 2: Concrete in Tension, CEB, Lausanne, Switzerland, p. 7.

Den Hartog, J. P. (1985), Mechanical Vibrations, Dover Publications, New York.

Dieterle, R. \& Bachmann, H. (1981), Experiments and Models for the Damping Behavior of Vibrating Reinforced Concrete Beams in the Uncracked and Cracked Conditions, Institut fur Baustatic und Konstruktion ETH, Zurich, Switzerland, Bericht Nr.119.

Doebling, S. W., Farrar, C. R., Prime, M. B. \& Shevitz, D. W. (1996), Damage Identification and Health Monitoring of Structural and Mechanical Systems from Changes in Their Vibration Characteristics: A Literature Review, Los Alamos National Laboratory, report LA-13070-MS.

Farrar, C. R. \& Jauregui, D. A. (1998a), Comparative study of damage identification algorithms applied to a bridge: I. Experiment, Smart Materials and Structures, 7, 704-19.

Farrar, C. R. \& Jauregui, D. A. (1998b), Comparative study of damage identification algorithms applied to a bridge: II. Numerical study, Smart Materials and Structures, 7, 720-31.

Feldman, M. (1994), Non-linear system vibration analysis using Hilbert transform-I. Free vibration analysis 'FREEVIB,' Mechanical Systems and Signal Processing, 8(2), 11927.

Feldman, M. (1997), Non linear free vibration identification via the Hilbert transform, Journal of Sound and Vibration, 208(3), 475-89.

Feng, M. Q. (2007), Recent advances in structural health monitoring, Journal of the Korean Society for Nondestructive Testing, 27(6), 483-500.

Franchetti, P. (2004), Vibration-based damage assessment of precast elements, Ph.D. thesis, DIMS, Università degli Studi, Trento, Italy.

Franchetti, P., Pavan, C. \& Modena, C. (2004), Vibrationbased damage assessment of precast elements, in Proceedings of 2nd European Workshop on Structural Health Monitoring, Munich, Germany, DESTech Publications Inc., July 7-9, 2004.

Frizzarin, M., Feng, M. Q., Franchetti, P. \& Modena, C. (2008), Damage detection based on damping analysis of ambient vibration data, Journal of Structural Control and Health Monitoring, DOI 10.1002/stc.296.

He, X., Babak Moaveni, B., Conte, J. P. \& Elgamal, A. (2008), Modal identification study of Vincent Thomas Bridge using simulated wind-induced ambient vibration data, ComputerAided Civil and Infrastructure Engineering, 23(5), 373-88.

Hunt, D. L., Weiss, S. P., West, W. M., Dunlap, T. A. \& Freemeyer, S. R. (1990), Development and implementation of a shuttle modal inspection system, Journal of Sound and Vibration, 24(9), 34-42.

Jiang, X. \& Adeli, H. (2005), Dynamic wavelet neural network for nonlinear identification of highrise buildings, Computer-
Aided Civil and Infrastructure Engineering, 20(5), 31630.

Jiang, X. \& Adeli, H. (2007), Pseudospectra, MUSIC, and dynamic wavelet neural network for damage detection of highrise buildings, International Journal for Numerical Methods in Engineering, 71(5), 606-29.

Jiang, X. \& Adeli, H. (2008a), Dynamic fuzzy wavelet neuroemulator for nonlinear control of irregular highrise building structures, International Journal for Numerical Methods in Engineering, 74(7), 1045-66.

Jiang, X. \& Adeli, H. (2008b), Neuro-genetic algorithm for nonlinear active control of highrise buildings, International Journal for Numerical Methods in Engineering, 75(7), 77086.

Jiang, X., Mahadevan, S. \& Adeli, H. (2007), Bayesian wavelet packet denoising for structural system identification, Structural Control and Health Monitoring, 14(2), 333-56.

Kim, J.-T. \& Stubbs, N. (2003), Crack detection in beam-type structures using frequency data, Journal of Sound and $V i$ bration, 259(1), 145-60.

Labview $^{\mathrm{TM}}$ (2000), Full Development System, Version 6.0, National Instrument Corporation, Austin, TX.

Lanaro, A. (2002), Indagine Teorico-Sperimentale su un Ponte Metallico con Unioni Chiodate del XIX Secolo: Analisi del Comportamento Dinamico, Bachelor degree thesis, DIMS, Università degli Studi, Trento, Italy.

Li, S. \& Wu, Z. (2008), A non-baseline method for damage locating and quantifying in beam-like structure based on dynamic distributed strain measurements, ComputerAided Civil and Infrastructure Engineering, 23(5), 40413.

Mahrenholtz, O. \& Bachmann, H. (1991), Appendix CDamping, Comite Euro-International du Beton-CEB, Lausanne, Switzerland, Bulletin n. 209, 169-80.

Moaveni, B. He, X. \& Conte, J. P. (2008), Damage identification of a composite beam based on changes of modal parameters, Computer-Aided Civil and Infrastructure Engineering, 23(5), 339-59.

Modena, C., Sonda, D. \& Zonta, D. (1998), Sulla Localizzazione del Danno Strutturale in Elementi di c. a. p., in Proc. XII Congresso CTE, Padova, 293-302.

Modena, C., Sonda, D. \& Zonta, D. (1999), Damage localisation in reinforced concrete structures by using damping measurements, in Proc. DAMAS99, Dublin, Key Engineering Materials, 167-68, Trans Tech Publications Ltd, June 28-30, 132-41.

Ni, Y. Q., Zhou, H. F., Chan, K. C. \& Ko, J. M. (2008), Modal flexibility analysis of cable-stayed Ting Kau Bridge for damage identification, Computer-Aided Civil and Infrastructure Engineering, 23(3), 223-36.

Pakrashi, V., O’Connor, A. \& Basu, B. (2007), A study on the effects of damage models and wavelet bases for damage identification and calibration in beams, ComputerAided Civil and Infrastructure Engineering, 22(8), 55569.

Park, H. S., Lee, H. M., Adeli, H. \& Lee, I. (2007), A new approach for health monitoring of structures: Terrestrial laser scanning, Computer-Aided Civil and Infrastructure Engineering, 22(1), 19-30.

Psimoulis, P. A. \& Stiros, S. C. (2008), Experimental assessment of the accuracy of GPS and RTS for the determination of the parameters of oscillation of major structures, Computer-Aided Civil and Infrastructure Engineering, 23(5), 389-403. 
Ren, W. X. \& De Roeck, G. (2002a), Structural damage identification using modal data. I: Simulation verification, Journal of Structural Engineering, 128(1), 87-95.

Ren, W. X. \& De Roeck, G. (2002b), Structural damage identification using modal data. II: Test verification, Journal of Structural Engineering, 128(1), 96-104.

Sohn, H., Kim, S. D. \& Harries, K. (2008), Reference-free damage classification based on cluster analysis, ComputerAided Civil and Infrastructure Engineering, 23(5), 324-38.

Sonda, D. (1999), Caratterizzazione dello Stato di Integrità di Strutture e Sottostrutture in c.a. e c.a.p. sulla Base dei Risultati di Prove Dinamiche, Ph.D. thesis, Università degli Studi G. D'Annunzio, Chieti, Italy.

Soyoz, S. \& Feng, M. Q. (2008), Instantaneous damage detection of bridge structures and experimental verification, To appear in Journal of Structural Control and Health Monitoring, 15(7), 958-73.
Stubbs, N. \& Kim, J.-T. (1996), Damage localisation in structures without baseline modal parameters, AIAA Journal, 34(8), 1644-49.

Swamy, R. N. (1971), Damping mechanisms in cementitious systems, Dynamic Waves in Civil Engineering, University College, Swansea, July 1970, Howells, D.A. Ed., Wiley Interscience, London, pp. 521-42.

Worden, K. \& Tomlinson, G. R. (2001), Nonlinearity in Structural Dynamics, Institute of Physics Publishing Ltd., Bristol and Philadelphia.

Zonta, D. (2000), Structural damage detection and localization by using vibrational measurements. Ph.D. thesis, DISTART, Università degli Studi, Bologna, Italy.

Zonta, D. \& Modena, C. (2001), Observations on the appearance of dispersive phenomena in damaged structures, Journal of Sound and Vibrations, 241(5), 92533. 